\title{
Estudo da Prevalência de cárie numa população de 0 a 5 anos atendida precocemente pela Bebê-Clínica da Universidade Estadual de Londrina
}

\author{
Study on the Incidence of Tooth Decay within a Population from \\ 0 to 5 Years Old early assisted by Universidade Estadual de Londrina \\ Bebê-Clínica
}

\begin{abstract}
GARBOZA, C.S.; WALTER, L.R.F. Estudo da Prevalência de Cárie numa População de 0 a 5 anos Atendida Precocemente pela Bebê-Clínica da Universidade Estadual de Londrina. Semina, Londrina, v. 18, ed. especial, p. 51-54, fev. 1997.
\end{abstract}

Celso Sebastião Garboza*

Luiz Reinaldo de Figueiredo Walter**

\begin{abstract}
RESUMO: O presente trabalho verificou a prevalência de cáne dentária em 287 crianças de 0 a 5 anos atendidas precocemente pela Bebê-Clínica da Universidade Estadual de Londrina. Antes da primeira consulta a população encontrava-se com grande risco de desenvolver cárie dentária, visto que $88,81 \%$ dos pacientes tinham o hábito de aleitamento noturno e $81 \%$ não realizavam higiene dental após a mamada notuma. Porém, depois da primeira consulta, com as devidas orientações sobre o hábito de aleitamento noturno e a higiene dental, verificou-se que a população estudada apresentou uma baixa prevalência de cárie, tanto do tipo mamadeira (0\%) quanto de cárie simples (2\%). Os resultados mostram a eficácia do atendimento precoce na promoção da saúde bucal nessa faixa etária.
\end{abstract}

PALAVRAS-CHAVE: Aleitamento Noturno; Higiene Dentária Noturna; Atendimento Precoce; Prevalência de Cárie.

ABSTRACT: The present study has verified the incidence of tooth decay in 287 children aged from 0 to 5 years old who had received early attention by the Bebê-Clinica of the Universidade Estadual de Londrina. Before the first appointment, the children had a high risk to develop caries, hence $88,81 \%$ of them had night milking habit and $81 \%$ were not used to dental hygiene after the last night milking, After their first appointment, due to orientation about night milking habit and dental hygiene, it was verified that the population studied presented low incidence of tooth decay in both baby bottle tooth decay (0\%) and simple caries (2\%). The results demonstrate the efficiency of early attention to promote the oral health at this age.

KEY WORDS: Night milking; Night dental hygine; Early attention; Caries prevalence.

\footnotetext{
Autor: Aluno do $5^{\circ}$ ano de Graduação em Odontologia da Universidade Estadual de Londrina.

k:ls Orientador: Livre-docente, Doutor em Odontopediatria/Professor Titular de Odontopediatria da Universidade Estadual de Londrina/Centro de Ciências da Saúdenat Pernarmbuco, 540) - Fonc (1443) 321-2002 - CEP 86120)-(170) - Londrina - Paranú.
} 


\section{INTRODUÇÃO}

Embora a Cariologia tenha avançado rapidamente nas últimas décadas, sabemos que os desafios para a primeira infância ainda são imensos e nessa faixa etária a cárie pode se manifestar de forma agressiva, levando à destruição completa da coroa dentária em um tempo surpreendentemente pequeno, podendo evoluir para quadros tão severos que interfiram negativamente no crescimento e desenvolvimento das crianças afetadas, trazendo transtornos físicos e emocionais para a criança.

Apesar de poucas pesquisas terem sido desenvolvidas nessa faixa etária, dados alertam para a alta freqüencia de cáric e para a urgência na definição de estratégias e ações capazes de prevenir e promover a saúde bucal. WALTER ct al ${ }^{10}$ (1987), demonstraram a alta prevalência de cárie $\mathrm{cm}$ crianças que compareceram à Clínica de Bebês da Universidade Estadual de Londrina (UEL) sendo que, na idade de 24 a 36 meses, lesões de cáries foram diagnosticadas em $62,96 \%$ das crianças. (GRANER et al ${ }^{3}$ (1994), pesquisando a cárie em crianças de 0 a 30 meses, na cidade de Piracicaba - SP, encontraram lesões de mancha branca na faixa etária de 7 a 12 meses e lesões cavitadas a partir dos 13 a 18 meses. Em determinadas populações, a cáric em idade precoce pode chegar a índices assustadores. ALBERT cr al' (1988) relataram o diagnóstico de cárie em crianças a partir dos 8 meses de idade, cm uma comunidade do Canadá, com grande prevalência de cáric, a qual atingiu $20 \%$ dos bebês de 18 meses, chegando à envolver $80 \%$ das crianças de 49 meses.

Além da cárie simples, existe também a cárie tipo mamadeira, que é uma forma de cárie rampante, onde muilos dentes estão envolvidos, com desenvolvimento rápido, ocorrendo em torno de nove meses de idade nas superlícics dentárias não susceptíveis a cárie. Segundo BABEELY el al ${ }^{2}$ (1989), a síndrome cárie de mamadeira tem por característica o fato de estar associado ao uso incontrolado e irrestrito principalmente noturno do aleitamento, tanto materno como artificial e também com o uso de chupetas adoçadas.

A prevalência dessa lesão chega a casos assustadores como os relatos de RIPA ${ }^{6}$ (1978), variando de 1 a 48\%, SCLAVOS et al 8 (1988) até $15 \%$, WALTER et al 10 (1987) relataram $18 \%$, e em populações indígenas acima de $50 \%$ segundo KELLY e BRUERD 4 (1987).

Porém, quando se fala em atender bebês, a população estranha e inicialmente pensa que a criança não tem problemas e que só deve ir ao dentista quando necessitar. PEREIRA 5 (1929) já enfatizava que era necessária uma propaganda sem limites no seio da família, pois a profilaxia deve começar desde a vida da criança no ventre materno com a formação dos órgãos dentários sadios e bem calcificados. Também ressaltava que os dentes, $\mathrm{cm}$ função da dificuldade de sua escovação, necessitavam de limpeza com gaze, envolvida no dedo, e embebida em solução de bicarbonato de sódio. Alertava, ainda, que a criança não deveria dormir logo após uma refeição sem antes lavar a boca e limpar os dentes, principalmente se os alimentos fossem açucarados.

Neste contexto se enquadra o atendimento realizado pela Bchê-Clínica da UEL, que atua na manutenção da saúde bucal através de 4 fundamentos básicos:

- atendimento precoce (de 6 a 12 meses);

- manutenção da saúde, antes da prevenção da doença;

- determinação do risco e controle por sua eliminação ou adequação;

- educação para os pais e prevenção para os fillhos.

Dessa forma, o trabalho visa estudar a prevalência de cárie (tanto simples como tipo mamadcira), numa população de 0 a 5 anos de idade, atendida precocemente pela Bebê-Clínica da UEL, avaliando a eficácia desse atendimento na promoção da saúde bucal.

\section{POPULAÇAOO MÉTODO}

Foram selecionadas ao acaso 360 fichas de pacientes atendidos no período de agosto de 1992 a outubro de 1994 pela Bebê-Clínica da UEL, através do programa de atendimento precoce, onde o paciente começa a ser atendido em torno de 6 meses de idade, tendo acompanhamento até 5 anos. 
Dessas fichas coletadas, 287 continham dados completos para o interesse da pesquisa, e através dessas executou-se a fase de levantamento de dados, através de entrevistas com as mães e estudos das fichas para tabulação e análise dos dados obtidos.

$\mathrm{Na}$ entrevista com mães foi verificado a respeito do hábito de aleitamento noturno e a existência ou não da higiene dental após a mamada.

\section{RESULTADOS}

Com a tabulação dos dados, verificou-se a prevalência de cárie simples e da síndrome cárie tipo mamadeira.

Antes da primeira consulta, constatou-se que a população apresentava grande risco de desenvolver cárie, principalmente tipo mamadeira, pois $88,81 \%$ dos pacientes tinham o hábito de aleitamento noturno (TABELA 1). Pesquisando as causas desse aleitamento constatou-sc que $72 \%$ o faziam simplesmente por costume e $27 \%$ por fome, choro e outros.

Quanto a realização da higiene dental nas crianças, $81 \%$ das mães não a realizavam (TABELA 1), ou por falta de conhecimento $(78 \%)$ ou por não achar necessário $(22 \%)$.

Desta forma, enquanto a prevalência de cáric nessa faixá ctária pode variar de 5 a 75\% (TOVERUD et al 9 , 1953), na população estudada encontramos o valor de $0 \%$ para a cáric tipo mamadcira e $2 \%$ para a cárie simples, ou scja, em valores absolutos, isto significa dizer que 287 pacientes, cncontramos somente 5 casos de cárie simples.

TABELA 1 - Presença ou não do hábito de aleitamento noturno e da higiene dental após a miamada.

\begin{tabular}{lcc} 
HÁBITO & ALEITAMENTO & HIGIENE \\
& NOTURNO & DENTAL \\
PRESENÇA & 88,81 & $\%$ \\
AUSÊNCIA & 11,19 & 19 \\
\hline
\end{tabular}

\section{DISCUSSÃO}

A prática da odontologia para bebês está fundamentada na aplicação do conceito de que a Educação gera a Prevenção. Para isso é importante trabalhar sobre o risco de cárie, através da educação dos pais, antes de qualquer ação direta sobre o bebê.

Dentre os fatores de risco, o relacionado com a amamentação é bem evidente, ROBINSON E NAYLOR 7 (1963), relataram que $87,88 \%$ dos bebês que faziam aleitamento na cama apresentaram dente(s) cariado(s) e apenas $12,12 \%$ não. Já os bebês que não faziam aleitamento na cama, 61,00\% deles não apresentaram dentes cariados. Dados semelhantes a estes foram obtidos por WALTER et al ${ }^{10}$ (1987), que em 345 bebês de 7 a 30 meses encontraram uma relação positiva entre hábitos alimentares noturnos e a instalação da cárie dentária onde $87,50 \%$ apresentavam cárie e apenas $12,50 \%$ não apresentavam.

Outro dado que chama a aîenção é que, em levantamentos realizados na Bebê-Clínica, de 1985 a 1990 WALTER et al ${ }^{11}$ (1996), onde as crianças cntravam no programa, tanto com cárie como sem ela, num estudo para analisar as causas da cárie, constatou-se que a mamada noturna, no primeiro ano de vida, determinava uma possibilidade de gerar cárie de $9,5 \% \mathrm{e}$, depois na idade de 13 a 24 meses, isso ocorreria em mais de $60 \%$ das crianças, demonstrando que, amamentar à noite, após certa idade, é de fato, um fator de risco. Esta análise foi realizada, também, com a limpeza e a escovação dentária e se observou que a ausência dessa no primeiro ano determina uma possibilidade da criança adquirir a cárie de $3 \%$, porém se não realizar a limpeza e/ou a escovação após 13 meses de idade, a possibilidade aumenta para $30 \%$, mostrando também, que a ausência de limpeza é um fator de risco.

\section{CONCLUSÃO}

Com a análise dos resultados, observou-se que houve 
uma reversão do risco de cárie quanto ao aleitamento noturno, por eliminação do hábito ou pela execução da higiene dental após a mamada.

Dessa forma, concluímos que através do atendimento precoce na educação e concientização dos pais, com as devidas orientações sobre a amamentação noturna e higiene dentária, é possível obter uma prevalência de $2 \%$ de cárie simples e de $0 \%$ de cárie tipo mamadeira, mostrando a eficácia do programa da Bebê-Clínica na promoção da saúde bucal nessa faixa etária, o que torna verdadeiro o slogan "Educar prevenindo, prevenir educando" WALTER E NAKAMA. ${ }^{12}$ (1992).

\section{REFERÊNCIAS BIBLIOGRÁFICAS}

1 - ALBERT, R. J.; CANTIN, R. Y.; CROSS, H. G.; CASTALDI, C. R. Nursing caries in the Inuit children of the Keewatin. J Canad dent Ass. v. 54, n. 10, p. $751-8$, oct. 1988 .

2 - BABEELY, K.; KASTE, L. M.; HUSAIN, I.; BEHBEHANI, J.; AL-ZAÁBI, F.L MAHER, T.C.; TAVARES, M.; SOPARKAR, P.; DEPAOLA, P. Severity of nursing-bottle sindrome and feeding patterns in $\mathrm{K}$ wait. Commum Dent oral Epidemiol. v.17, n.5, p.237-9.

3 - GRANER, R. O. M.; RONTANI, R. M. P.; GAVIÃO, M. B. D.; BOCATTO, H. C. A. R. Prevalence of dental caries in $0-3$ year old children of Piracicaba - Brazil. In: International Association for Rental Research. Brazilian Socicty for Dental Research Annual Meeting. XI Águas de São Paulo, sept. 47, 1994. Abstiacts of Papers. Chicago, J Dent Res, v.74, n. 3, p.785, 1994.

4 - KELLY, M.; BRUERD, B. The prevalence of baby bottle tooth decay among two native american populations. J. Public Health Dent. v.47, p.947, 1987.
5 - PEREIRA, D. B. Educação dentária da criança. Rio de Janeiro, 1929, 79 p.

6 - RIPA, L. W. Nursing habits and dental decay in infants: "nursing bottle caries". J. Dent Chield. v.45, n.4, p.274-5, july/aug. 1978.

7 - ROBINSON, S.; NAYLOR, S.R. The effect of late weaning on the deciduos incisors teeth: a pilot survey. Brit dent J. v.115, n.6, p.250-2, sept., 1963.

8 - SCLAVOS, S.; PORTER, S.; SEOW, W. K. Future caries development in children with nursing bottle caries. J. Pedod. v.13, n.1, p.1-10, 1988.

9 - TOVERUD, G.; FINN, S. B.; COX, G. I.; BODECKER, C. F.; SHAW, J. H. Survey of the literature of dental caries. Washington, D. C.: National Academy of Sciences - National Research Council, 1953.

10 - WAITER, L. R. F.; FERELLE, A.; HOKAMA, N.; PELANDA, V. L. G.; FRANCO, M. P. S.; IEGA, R. Cárie em crianças de 0 a 30 meses de idade $e$ sua relação com habitos alimentares. Encyl bras Odontol. v.5, n.1, p.129-36, 1987.

11 - WALTER, L. R. F.; NAKAMA, L. Paciente de alto indice de cárie versus paciente de alto risco: qual a conduta? In: BOTINO, M. A.; FELLER, C. Atualização na clínica odontológica. São Paulo: Artes Médicas, 1992. Cap.18, p.251-258.

12 - WALTER, L. R. F.; FERELLE, A.; ISSAO, M. Odontologia para o bebê. 1.ed. Artes Médicas, 1996.

Trabalho apresentado ao $\sigma^{\circ}$ Prêmio Estínulo Kolynos 